\title{
The provincial power grid monthly purchasing risk management model based on Monte-Carlo stochastic simulation technology and wind power uncertainty
}

\author{
Wang Junmei ${ }^{1, a}$, Guo Lin ${ }^{1, b}$ Ma Chao ${ }^{1, c}$ Gao Chuncheng ${ }^{2, d}$ Liu Dunnan $^{3, e}$ and \\ Yang $\mathrm{Mo}^{3, \mathrm{f}}$ \\ ${ }^{1}$ State Grid Chongqing Electric Power Corporation, Chongqing 400014, China; \\ ${ }^{2}$ Nari Group Corporation/State Grid Electric Power Research Institute, Nanjing 210003, China. \\ ${ }^{3}$ North China Electric Power University, Beijing 102206, China. \\ a wjm@cq.sgcc.com.cn, b GL681001@cq.sgcc.com.cn, ${ }^{\mathrm{c}} \mathrm{mc} @ c q . s g c c . c o m . c n$, \\ dgaochuncheng@sgepri.sgcc.com.cn, ${ }^{\mathrm{e}}$ liudunnan@163.com, ${ }^{f}$ momo_20080707@sina.com
}

Keywords: electricity market, monthly power-purchasing plan, risk management, uncertainty of wind power generation, provincial power grid, Genetic Algorithm.

\begin{abstract}
Considering the uncertainty of wind power generation in the context of the regional electricity market, the risk quantitative index and risk management model for the monthly electricity purchasing plan considering the uncertainty of wind power generation is proposed. First, based on the risk measure index of the monthly peak and light load with the wind power output uncertainty, monthly peak load and light load state branch power flow is limited, and upper and lower bounds on the monthly electricity balance, which established provincial grid monthly electricity purchasing optimization model of purchase the smallest electricity cost and risk value. Secondly, aiming at the characteristics of the built model for multi-objective model and the index of risk measurement, the model is solved by the hybrid genetic algorithm which is based on the relative dominance of the embedded object and the Monte-Carlo stochastic simulation technology. Finally, a numerical example shows the effectiveness of the above mentioned work.
\end{abstract}

$\mathrm{s}$ verified by the case of test research.

\section{Introduction}

Under the electricity market, the study of monthly power-purchasing plan has important practical significance to the economic achievement of power grid companies[1,2].

In view of this, this paper carried out pioneering research in the following two aspects: 1) the establishment of several risky indexes, and they were represented as monthly the highest and lowest peak load, monthly violated transmission power when carrying the highest and lowest peak load and monthly violated power-balance, respectively ; 2) the establishment of provincial power grid monthly power-purchasing risk management model. Finally, the proposed model's effectiveness was verified by testing study cases, and a new idea was provided for optimization decision of provincial grid monthly power-purchasing plan under the uncertain wind power output environment.

\section{A monthly Power Purchasing Risk Management Model for Provincial Power Grid}

\subsection{Modeling principles and assumptions}

The risk quantitative indexes built in the last section can be used in monthly power-purchasing plan model to realize the risk management of power-purchasing. Stochastic programming model with chance constraints is essentially consistent with the risk control theory pursued in this paper. Based on this, the physical connotation of the model can be described as follows: with the uncertainty of wind power output, load power, putting the risk quantitative indexes below a certain level of probability can realize the maximum economic achievement of provincial power grid monthly power-purchasing plan[4]. 
Without loss of generality, the model also make the following assumptions $[3,4]: 1)$ under the state of peak load and valley load, the wind power output and load power, monthly wind power, power capacity, internal thermal power and external power-purchasing unit price are obey normal distribution independently; 2) before the monthly auction trading, the decomposition electricity in month of annual purchasing electricity has been completed, the model is no longer represented separately; 3 ) ignoring transaction costs and transmission losses.

2.2 The establishment of model

(1) The objective function

Using the minimum power-purchasing cost of provincial power grid in monthly regional electricity market and internal electricity market as the objective function; At the same time considering the existence of random factors such as market price, monthly wind power and load capacity can lead to certain risks of power-purchasing cost, using semi-absolute deviation risk index [4] to measure the corresponding risk of purchasing cost, thus the power-purchasing cost and risk value of objective function in the model are as follows:

$$
\begin{aligned}
& \min \sum_{k=1}^{N_{\mathrm{w}}} u_{\mathrm{w}, k} W_{\mathrm{w}, k}+\sum_{k=1}^{N_{\mathrm{t}}} u_{\mathrm{t} . k} W_{\mathrm{t} . k}+\sum_{k=1}^{N_{\mathrm{ex}}} u_{\mathrm{ex}, k} W_{\mathrm{ex}, k}
\end{aligned}
$$

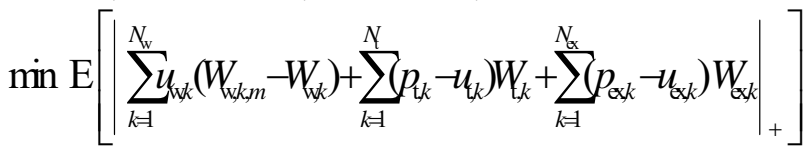

In the formula, $\mathrm{E}$ [ ] represents the expectation operator; $\mathrm{u}_{\mathrm{w}, \mathrm{k}}$ represents the electricity price of the number $\mathrm{k}$, wind power unit; $\mathrm{u}_{\mathrm{t}, \mathrm{k}}$ represents the electricity price expectation of the number $\mathrm{k}$ thermal power unit; $u_{e x, k}$ represents the electricity price expectation of the number $k$ external power-purchasing unit; $\mathrm{w}_{\mathrm{w}, \mathrm{k}}$ represents the monthly electricity expectation of the number $\mathrm{k}$ wind power unit; $p_{t, k}$ and $p_{e x, k}$ represents the random electricity price of the number $k$ thermal unit and the external power-purchasing unit respectively.

The "+" of ||$_{+}$in formula (2) means that there would be risk when the total power-purchasing cost in formula (1) "exceed" the expectation.

(2) Constraints

1) System power flow security constraints

2) The DC power flow balance equation under the state of monthly peak load and valley load

$$
\boldsymbol{P}_{\mathrm{w}, \mathrm{s}}+\boldsymbol{P}_{\mathrm{t}, \mathrm{s}}+\boldsymbol{P}_{\mathrm{ex}, \mathrm{s}}-\boldsymbol{P}_{\mathrm{d}, \mathrm{s}}=\boldsymbol{B} \boldsymbol{\delta}_{\mathrm{s}} \quad \boldsymbol{S}=1,3
$$

In the formula, $\mathrm{p}_{\mathrm{w}, \mathrm{s}}, \mathrm{p}_{\mathrm{t}, \mathrm{s}}, \mathrm{p}_{\mathrm{ex}, \mathrm{s}}$ and $\mathrm{p}_{\mathrm{d}, \mathrm{s}}$ represents the power vector of wind power unit, thermal unit, external power-purchasing and load node under the condition of s load respectively; B represents the node admittance matrix; s represents the voltage angle vector under the condition of $\mathrm{s}$ load; the expression of power-purchasing outside node is:

$$
P_{\text {ex }, s, i}=\sum_{k \in \Phi_{i}} P_{\text {ex }, s, k} \quad i=1, \ldots, N ; s=1,3
$$

In the formula, $\mathrm{p}_{\mathrm{ex}, \mathrm{s}, \mathrm{j}}$ represents the external power-purchasing power of node $i$ under the condition of $s$ load; $\mathrm{p}_{\mathrm{ex}, \mathrm{s}, \mathrm{k}}$ represents the power of number $\mathrm{k}$ external power-purchasing unit under the condition of s load; represents the external power-purchasing unit set associated with node i; $\mathrm{N}$ represents the total node number of system.

b) The branch power flow equation under the state of monthly peak load and valley load

$$
P_{s, l}=\left(\delta_{s, i}-\delta_{s, j}\right) / x_{i j} \quad l=1,2, \ldots, N_{l} ; s=1,3
$$

In the formula, $\mathrm{p}_{\mathrm{s}, \mathrm{j}}$ represents the transmission power of branch 1 under the condition of $\mathrm{s}$ load; $\delta_{\mathrm{s}, \mathrm{i}}$ and $\delta_{\mathrm{s}, \mathrm{j}}$ represents voltage angle of the beginning node $\mathrm{i}$ and the end node $\mathrm{j}$ in branch 1 under the condition of s load respectively; $\mathrm{x}_{\mathrm{ij}}$ represents the reactance of branch 1 . 
c) The branch power flow risk management constraints under the state of monthly peak load and valley load

$$
\begin{array}{ll}
\alpha_{1, l} \leq \alpha_{1, l, \max } & l=1,2, \ldots, N_{l} \\
\alpha_{3, l} \leq \alpha_{3, l, \max } & l=1,2, \ldots, N_{l}
\end{array}
$$

In the formula, and represents the limit value of branch 1 power flow limit level under the state of peak load and valley load respectively. According to the literature, the formula (2) (4) can be converted to the sensitivity expressed in formula (4), and then combined with formula (6) (7) can achieve the branch power flow risk management of monthly power-purchasing plan.

2) The peak-shaving risk management constraints under the state of monthly peak load and valley load

$$
\begin{aligned}
& \beta_{1} \leq \beta_{1, \text { mx }} \\
& \beta_{3} \leq \beta_{3, \text { max }}
\end{aligned}
$$

In the formula, $\beta_{1, \max }$ and $\beta_{3 \cdot \max }$ represents the limit value of peak-shaving risk level under the state of peak load and valley load respectively.

3) Regional electricity market external power-purchasing unit constraints

a) The power and energy coupling relationship between external power-purchasing units According to the coupling relationship between provincial power grid monthly external purchasing power and energy based on literature $[17,18]$, the coordination relationship between monthly external purchasing electricity and peak and valley electricity can be expressed as follows:

$$
W_{\mathrm{ex}, k}=\sum_{s=1}^{3}\left(\alpha_{s} \times P_{\mathrm{ex}, 1, k} \times T_{s} \times D\right) \quad k=1,2, \ldots, N_{\mathrm{ex}}
$$

In the formula, $\alpha$ s represents the ratio of external power-purchasing power under the condition of $s$ load and the condition of peak load; Pex, 1,k represents power of number k external power-purchasing unit under the condition of peak load; Ts represents the power-purchasing hours in one day under the condition of three kinds of load state; D represents the actual number of days of power-purchasing month.

b)The price pattern options of external power-purchasing unit

Determining the price pattern options of external power-purchasing unit based on the inter provincial trading price pattern of same offer with peak and valley load in central regional electricity market, as follows:

$$
C_{\mathrm{ex}, k}= \begin{cases}C_{\mathrm{ex}, k, 1} & \text { if } \sigma_{1}: \sigma_{2}: \sigma_{3}=1.0: 1.0: 1.0 \\ C_{\mathrm{ex}, k, 2} & \text { if } \sigma_{1}: \sigma_{2}: \sigma_{3}=1.0: 1.0: 0.9 \\ \cdots & \\ C_{\mathrm{ex}, k, n} & \text { if } \sigma_{1}: \sigma_{2}: \sigma_{3}=1.0: \underline{\sigma}_{2}: \underline{\sigma}_{3}\end{cases}
$$

In the formula, cex, $\mathrm{k}, \mathrm{n}$ represents the power price expectation of purchasing pattern $\mathrm{n}$ of external power-purchasing unit $\mathrm{k}$; $\mathrm{n}$ represents purchasing patter number of external power-purchasing unit; and represents the lower limit of the ratio of external power-purchasing power under the condition of valley load and the condition of peak load respectively.

c) The power constraint of external power-purchasing unit

$$
0 \leq P_{\text {ex }, s, k} \leq P_{\text {ex }, k, \max } \quad k=1,2, \ldots, N_{\text {ex }} ; \quad s=1,2,3
$$

In the formula, represents the maximum power of external power-purchasing unit $\mathrm{k}$.

3) The risk management constraints of monthly electricity balance limits

$$
\begin{aligned}
& \gamma_{1} \leq \gamma_{1, \max } \\
& \gamma_{3} \leq \gamma_{3, \max }
\end{aligned}
$$

In the formula, and represents the upper and lower limit of monthly electricity balance limits respectively.

4) The internal power-purchasing unit constraints 
In the monthly power-purchasing plan, because of the decoupling relationship between power and electricity of internal power-purchasing thermal unit, it would be good as long as the month electricity consumption within the unit power range, whereby the internal thermal unit power and electricity constraints can be expressed respectively as formula ( 15) (16).

a) The upper and lower power limit constraints of thermal units

$P_{\mathrm{t}, k \text { min }} \leq P_{\mathrm{t}, \mathrm{s}, \mathrm{k}} \leq P_{\mathrm{t}, k, \max } \quad k=1,2, \ldots, N_{\mathrm{t}} ; \mathrm{s}=1,3$

b) The upper and lower electricity limit constraints of thermal units

$W_{\mathrm{t}, k, \min } \leq W_{\mathrm{t}, k} \leq W_{\mathrm{t}, k, \max }$

In the formula, and represents the upper and lower electricity limit of the number $\mathrm{k}$ thermal unit respectively, this electricity has already contained the month decomposition electricity from annual power-purchasing plan of this thermal unit.

\section{Embedded target relative dominance and Monte-Carlo simulation of hybrid genetic algorithm}

3.1 Fitness function based on chromosome target relative dominant

The model is multi-objective and the class model [5] is proposed based on the target relative dominant genetic algorithm to obtain the optimal solution of its comprehensive. The idea is the population of each chromosome are sorted according to each sub-objective function value and select each iteration so that each sub-objective function value the smallest chromosome and not 0 as the starting point of each sub-objective function. Then calculated for each chromosome opposite each point of the target value. The best sum of target value is each iteration of the best chromosome.

$$
A\left(x_{i}\right)=1 /\left(F\left(x_{i}\right)+\sum_{j=1}^{N_{y}}\left(\omega_{j} \times g_{j}\left(x_{i}\right)\right)\right)
$$

In the formula, $A\left(x_{i}\right)$ is fitness function of chromosome $\left(x_{i}\right), g_{j}\left(x_{i}\right)$ is penalty function, $\mathrm{w}_{\mathrm{j}}$ is coefficient of penalty function. If $g_{j}\left(x_{i}\right)$ satisfy the constraints, $\mathrm{w}_{\mathrm{j}}$ is 0 .

$$
F\left(x_{i}\right)=\sum_{j=1}^{N_{j}}\left(f_{j}\left(x_{i}\right) / f_{j}\left(x_{j_{-} 0}\right)\right)
$$

In the formula, $f_{j}\left(x_{i}\right)$ represents a function of the value of the corresponding sub-chromosome $x_{i}$ of the objective function $\mathrm{j}$.

3.2 Embedded target relative dominance and Monte-Carlo simulation technology specific steps GA

The model of the control variables for the month of electricity purchased power units, Each thermal power units monthly capacity, all thermal power peak load, charge status output Valley, and state variables for the system peak load and valley load status of each node voltage phase angle. Thus, the use of embedded target relative dominant genetic algorithm model and Monte-Carlo simulation technique, the main steps are as follows.

1)Enter the original data. Enter each risk level metrics limit the underlying data in each network unit and purchased power unit market price, the grid structure, and chromosomal genetic algorithm requirements (candidate purchase program) the number of crossover probability and mutation probability algorithm parameter values.

2) Initial population. Generates a random purchase program (all purchased electricity peak load power status of each thermal power units within the network peak load and valley load output, thermal power within the network each month electricity) as the initial population of the genetic algorithm.

3) Using Latin hypercube sampling inspection risk management constraints. The population of each chromosome, using the Latin hypercube sampling technique to produce a large number of wind power peak load and valley load output, wind power monthly electricity load monthly electricity, peak load and valley load load power samples, testing the various risk management constraints which meets. 
4) Calculated using the target relative fitness dominant approach. Found this iteration so that each sub-objective function value without sorting first chromosome as a base point 0 .

5) Select Options. Roulette method of population of chromosomes select Options.

6) Crossover and mutation operation. The population of chromosomes crossover and mutation operations to give a new generation of chromosomes, similar to the step 3), then using the Latin hypercube sampling inspection risk of constraints.

7) Get the best purchase program. Repeat steps 3) to step 6), until it reaches a given iteration termination criterion is reached. Integrated optimal chromosome found in the solution process as the final purchase program (allocation of each thermal power units within the network of electricity, distribution of electricity each purchased power units, the total purchase cost, risk, value at risk as well as the evaluation index information).

\section{Example verification}

\subsection{Basic data}

Using the basic data of a provincial power grid company to carry out the monthly power-purchasing plan simulation to verify the effectiveness of the research work in this paper. The monthly load electricity demand expectation of this power grid is $4.506 \mathrm{GkW} \mathrm{h}$, the standard deviation is $0.09012 \mathrm{GkW} \quad \mathrm{h}$; the system peak load, valley load power is $8000 \mathrm{MW}$ and $6000 \mathrm{MW}$; the monthly wind power electricity expectation is $0.700 \mathrm{GkW} \mathrm{h}$, the standard deviation is 0.14 GkW h, the monthly wind power output expectation under the state of peak load and valley load is $600 \mathrm{MW}$ and $800 \mathrm{MW}$, the standard deviation is $20.0 \%$ of the corresponding expectation, the wind power electricity price is 560.0 yuan $/ \mathrm{MW} \mathrm{h}$; the internal thermal power electricity price expectation is 379.3 yuan / MW h, the standard deviation is 30.0 yuan / MW h; the data of external power-purchasing unit is seen in literature [4]; the basic data of power grid structure is known. To facilitate the simulation, each risk level limit is taken $10.0 \%$.

4.2 The analysis of model

Simulation results based on section 3.1 Simulation conditions are as shown in Table 1. In view of the fact that there are lots of branches in the actual power grid, the branch power flow risk quantitative index is only selected from a certain key branch of the power grid load center for analysis (after the same).

Table.1 The simulation results of monthly power-purchasing plan

\begin{tabular}{|c|c|c|c|c|c|c|c|c|}
\hline & $\begin{array}{l}\text { Purchasin } \\
\mathrm{g} \\
\text { electricity } \\
\text { cost } \\
\text { /Billion } \\
\text { yuan }\end{array}$ & $\begin{array}{l}\text { Risk value } \\
\text { /Billion } \\
\text { yuan }\end{array}$ & $\begin{array}{l}\text { The risk } \\
\text { of } \\
\text { peak-shav } \\
\text { ing under } \\
\text { the peak } \\
\text { load state }\end{array}$ & $\begin{array}{l}\text { The risk of } \\
\text { peak-shavi } \\
\text { ng under } \\
\text { the valley } \\
\text { load state }\end{array}$ & $\begin{array}{l}\text { The branch } \\
\text { limit risk } \\
\text { under the } \\
\text { peak load } \\
\text { state }\end{array}$ & $\begin{array}{l}\text { The branch } \\
\text { limit risk } \\
\text { under the } \\
\text { valley load } \\
\text { state }\end{array}$ & $\begin{array}{l}\text { The upper } \\
\text { limit risk } \\
\text { under the } \\
\text { condition of } \\
\text { monthly } \\
\text { electricity } \\
\text { balance }\end{array}$ & $\begin{array}{l}\text { The lower } \\
\text { limit risk } \\
\text { under the } \\
\text { condition of } \\
\text { monthly } \\
\text { electricity } \\
\text { balance }\end{array}$ \\
\hline Literature[3] & 18.5661 & 2.5189 & $17.9 \%$ & $21.6 \%$ & $18.6 \%$ & $16.6 \%$ & $8.8 \%$ & $6.1 \%$ \\
\hline Literature[4] & 19.2266 & 2.7921 & $0.0 \%$ & $0.0 \%$ & $0.0 \%$ & $0.0 \%$ & $0.0 \%$ & $0.0 \%$ \\
\hline This paper & 18.9888 & 2.6658 & $2.2 \%$ & $5.6 \%$ & $2.9 \%$ & $6.2 \%$ & $6.3 \%$ & $2.8 \%$ \\
\hline
\end{tabular}

In the monthly power-purchasing plan of grid power system include the wind power output uncertainty, the introduction of risk management strategy has the rationality and practicability, and can meet the development need of power market.

\section{Conclusion}

Under the background of regional electricity market, and the uncertainty of wind power output, the provincial power grid monthly power-purchasing risk quantitative index and risk management model are established, the research conclusion is as follows:

1) Under the environment that the wind power output has randomness, the implementation of the provincial power grid power-purchasing plan will have a certain level of risk, the introduction of risk management concept is necessary at the moment. 
2) The risk quantitative indexes can measure the risk of monthly power-purchasing plan effectively, such as the peak-shaving under peak load and valley load state, the branch power flow limit risk under the monthly peak load and valley load, the upper and lower limit risk under the condition of monthly electricity balance, and they have enriched the physical connotation of power market risk indexes.

3) The monthly power-purchasing risk management model of provincial power grid, can achieve the effective management of economic benefits and risks, and provide a new idea for the future large-scale wind power into the monthly electricity and energy balance.

\section{References}

[1]HUANG Yonghao, SHANG Jincheng, KANG Chongqing, et al. An operation mechanism and model of long and middle term contract market[J]. Automation of Electric Power Systems,2003, 27(4):1-6.

[2]SHANG Jincheng, Mechanism and risk control strategies for trans-regional and trans-provincial power exchange[J]. Automation of Electric Power Systems, 2010, 34(19):52-57.

[3] WEN Xu, YAN Wei, WANG Junmei, et al. Regional energy-Saving electricity market and stochastic programming power purchasing model considering assessment on energy consumption in trans-provincial transaction[J]. Power System Technology, 2013,37 (2):500-506.

[4] YAN Wei, WEN Xu, WANG Junmei, et al. An optimal monthly power purchasing model considering differences between Internal and external grid[J]. Automation of Electric Power Systems, 2012, 36(17): 56-60.

[5] LIN ye, Studies on optimization of global generation and transmission maintenance scheduling and its security correction[D]. Chongqing: Chongqing university, 2011. 